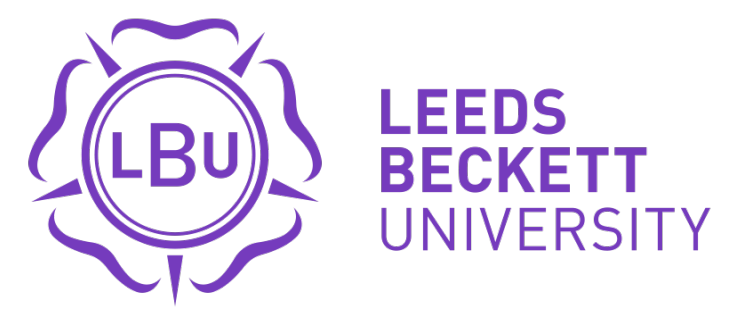

Citation:

Darrall-Jones, J and Jones, B and Roe, G and Till, K (2016) Reliability and Usefulness of Linear Sprint Testing in Adolescent Rugby Union and League Players. Journal of strength and conditioning research / National Strength \& Conditioning Association, 30 (5). 1359 - 1364. ISSN 1064-8011 DOI: https://doi.org/10.1519/JSC.0000000000001233

Link to Leeds Beckett Repository record:

https://eprints.leedsbeckett.ac.uk/id/eprint/2503/

Document Version:

Article (Accepted Version)

This is an Accepted Manuscript of an article published in Journal of Strength and Conditioning Research, May 2016, available online: https://doi.org/10.1519/JSC.0000000000001233

The aim of the Leeds Beckett Repository is to provide open access to our research, as required by funder policies and permitted by publishers and copyright law.

The Leeds Beckett repository holds a wide range of publications, each of which has been checked for copyright and the relevant embargo period has been applied by the Research Services team.

We operate on a standard take-down policy. If you are the author or publisher of an output and you would like it removed from the repository, please contact us and we will investigate on a case-by-case basis.

Each thesis in the repository has been cleared where necessary by the author for third party copyright. If you would like a thesis to be removed from the repository or believe there is an issue with copyright, please contact us on openaccess@leedsbeckett.ac.uk and we will investigate on a case-by-case basis. 


\section{Reliability and Usefulness of Linear sprint testing in adolescent Rugby Union and League players}

Running Head: Reliability of linear sprint testing in youth Rugby players

Joshua David Darrall-Jones, Ben Jones, Gregory Roe and Kevin Till

Research Institute Sport, Physical Activity and Leisure, Leeds Beckett University, Leeds, West Yorkshire, United Kingdom

\section{Corresponding Author:}

Joshua Darrall-Jones

Room G03, Macaulay Hall

Research Institute for Sport, Physical Activity and Leisure

Centre for Sports Performance

Headingley Campus, Leeds Beckett University

W.Yorkshire, LS6 3QS

Phone: (0044) 7878598083

Email: J.Darrall-Jones@leedsbeckett.ac.uk 


\begin{abstract}
The purpose of the present study was to evaluate; 1) whether there were differences in sprint times at 5, 10, 20, 30 and 40 m between rugby union and rugby league players; 2) determine the reliability and usefulness of linear sprint testing in adolescent rugby players. Data were collected on 28 rugby union and league academy players over two testing sessions, with three day's rest between sessions. Rugby league players were faster at $5 \mathrm{~m}$ than rugby union players, with further difference unclear. Sprint time at 10, 20, 30 and $40 \mathrm{~m}$ were all reliable $(\mathrm{CV}=3.1 \%, 1.8 \%, 2.0 \%$ and $1.3 \%)$ but greater than the smallest worthwhile change (SWC $(0.2 \mathrm{x}$ between-subject $S D))$, rating the test as marginal for usefulness. While the test was incapable of detecting the SWC we recommend that practitioners and researchers use Hopkins' proposed method (22); whereby plotting the change score of the individual at each split ( \pm TE expressed as a CV) against the SWC, and visually inspecting whether the TE crosses into the SWC is capable of identifying whether a change is both real (greater than the noise of the test, i.e., >TE) and of practical significance (>SWC). Researchers and practitioners can use the TE and SWC from the present study to assess changes in performance of adolescent rugby players when using single beam timing gates.
\end{abstract}

Key Words: Testing, Evaluation, Sprint, Rugby, Reliability 


\section{INTRODUCTION}

Physical testing is implemented in professional sports worldwide to assist in the prescription and evaluation of training interventions (27). The outcome of testing is used to profile individuals against norms for their position within the respective sports $(12,30)$. The data are used to provide valuable insights into factors that may contribute to and regulate exercise performance, and should be considered complimentary in guiding the preparation of individuals to improve their physical potential; thus allowing them to tolerate the demands of training and match-play to excel in their chosen sport (27). Following training interventions, individuals are commonly reassessed to understand to what extent the intervention has had an effect; this is often upon the completion of the pre-season preparatory phase before competition begins.

It is also recommended that practitioners working with adolescent athletes should monitor changes in physical qualities (e.g., linear sprint times), to allow informed decisions to be made regarding the progression of athletes (30). Although assessment of interventions and player progression is common through sprint testing, understanding the error of the test and what constitutes a worthwhile change has not been investigated in adolescent rugby players.

Linear sprint testing is common for athletes $(3,4,17,24,32)$. It is assumed that distances of 5 to $10 \mathrm{~m}$ can be used to assess an individual's ability to accelerate, while maximal velocities are considered to manifest between 20 and $40 \mathrm{~m}(3,4,32)$. While sprint time in isolation may not be considered a discriminate physical quality, it has been highlighted as influencing whether players start in Australian rules football (AFL), alongside measures of leg power, and high intensity running ability (32). To this end, it is used in the physical testing battery designed to distinguish the best American Football prospects in the draft (24). 
Improvements in sprint times following an eight week sprint training block in rugby league players demonstrated moderate $(E S=-0.60)$ improvements at $10 \mathrm{~m}$ (pre $=1.84 \mathrm{~s}$; post $=1.79 \mathrm{~s} ;-2.62 \%)$ and $20 \mathrm{~m}(\mathrm{ES}=-0.69 ;$ pre $=3.25 \mathrm{~s} ;$ post $=3.17 \mathrm{~s} ;-2.35 \%)$, and small $(\mathrm{ES}=$ $-0.50)$ improvements at $40 \mathrm{~m}($ pre $=5.55 \mathrm{~s} ;$ post $=5.45 \mathrm{~s} ;-1.94 \%)(29)$, demonstrating expected changes in sprint time with a specific sprint training intervention.

Despite the importance placed upon sprint time, between day reliability is rarely reported, suggesting that both researchers and practitioners are unaware when a change is real (26). Hopkins (22) suggests that the use of the typical error (TE) alongside the smallest worthwhile change (SWC $(0.2 \mathrm{x}$ between-subject $S D)$ based on Cohen's $d$ effect size principle) (10) allows practitioners to make well informed decision as to whether a change is both real (greater than the noise of the test, i.e., $>$ TE) and of practical significance ( $>$ SWC).

This has been addressed in rugby union (14) over a distance of $10 \mathrm{~m}$ using three different starting techniques, with the authors concluding that there is only a marginal chance of reliably detecting a worthwhile change due to the TE $(\sim 0.02 \mathrm{~s})$ being greater than the SWC $(0.002 \mathrm{~s})$. While the authors (14) state that the SWC needs to be established within a specific population, there appear to be a number of limitations in the method by which it is calculated, and therefore calls the results into question. The authors state that elite rugby union players demonstrate a coefficient of variation (CV) of $0.6 \%$ in sprint time (13), and proceed to use this in the calculation of SWC, stating that it is $\sim 0.002 \mathrm{~s}$. However, it appears the CV has been calculated from a $40 \mathrm{~m}$ sprint (13), questioning the usefulness of this in calculating the SWC for a $10 \mathrm{~m}$ sprint. Further, the authors use $10 \mathrm{~m}$ sprint time data $(1.75 \mathrm{~s})$ from recreationally active physical education students (25), and not rugby players. Both the $\mathrm{CV}(0.6 \%)$ and $10 \mathrm{~m}$ sprint time $(1.75 \mathrm{~s})$ are then used to calculate a between-subject $S D$ $(1.75 \times 0.6 \%)$ and multiplied by 0.2 to give the SWC. As it is suggested that both TE and SWC are population specific (26), it would seem that for a true understanding of the 
relationship between the TE and SWC in a $10 \mathrm{~m}$ sprint, the authors should have calculated the SWC within their own population to then give recommendations applicable to professional rugby union players.

In contrast, Gabbett (16) has been cited (28) as reporting interday TE of sprint times for 10, 20, 30 and $40 \mathrm{~m}$ in semi-professional rugby league players as $2.07 \%, 1.52 \%, 1.91 \%$ and $1.25 \%$ respectively. Upon review of the methods, all testing was completed intraday, suggesting that this data cannot be used to make decisions on changes in performance in rugby league players.

Alongside between-day reliability, standardization of tests is necessary, with recent research reporting differences in $5 \mathrm{~m}$ sprint times with varying start positions; $30 \mathrm{~cm}, 50 \mathrm{~cm}$ and $100 \mathrm{~cm}$ behind the start (1). The authors report no significant difference $(p=0.175)$ between the $30 \mathrm{~cm}$ and $50 \mathrm{~cm}$ start position in $5 \mathrm{~m}$ sprint time, or initial timing gate error $(p=$ 0.397). The data provided demonstrate a small effect $(\mathrm{ES}=0.52 \pm 0.65)$ suggesting that 50 $\mathrm{cm}$ start position improves sprint time compared to the $30 \mathrm{~cm}$ start position. Whilst the confidence interval associated with the effect size for initial error $(E S=0.43 \pm 0.65)$ suggests that the differences are unclear (20). This suggests that whilst the differing start positions at $30 \mathrm{~cm}$ and $50 \mathrm{~cm}$, effect sprint time, they do not necessarily effect the accuracy of measures, therefore either can be used, as long as this is standardized across all testing.

Due to methodological errors (14) and misinterpretation of TE data (28); it appears that between-day TE and SWC data need to be generated for linear sprint testing in rugby union and rugby league populations. This will allow practitioners to make informed decisions on testing data, and further allow researchers to report individual changes in response to training interventions. Furthermore, it has been suggested, that due to time constraints within 
professional sport, that it is acceptable to use the TE and SWC generated from a similar population to determine changes in athletic performance $(7,26)$

Therefore the purpose of the study was to calculate the TE and SWC of 5, 10, 20, 30 and $40 \mathrm{~m}$ sprint splits to evaluate reliability and usefulness of linear sprint testing in adolescent rugby players. Further, the study aimed to identify the ability of the test to detect a practically important change, and to report reference TE and SWC values for adolescent rugby players. In addition, the study provides an example of how practitioners can interpret their data by using the TE and SWC to determine when a change is real.

\section{METHODS}

\section{Experimental Approach to the Problem}

Junior rugby union players from a professional regional academy in the UK, and junior rugby league players from a professional Super League club in the UK were assessed for 5, 10, 20, 30 and $40 \mathrm{~m}$ sprint time on two occasions at the same time of day, in similar environmental conditions with three day's rest between sessions. Players refrained from physical activity for forty-eight hours prior to each testing sessions and maintained their normal dietary habits. Testing was completed on an outdoor $3^{\text {rd }}$ generation $(3 \mathrm{G})$ playing surface with all participants wearing the same studded footwear on both occasions. Reliability of the test variables during the two sessions was assessed using the TE of measurement expressed as raw data and as a coefficient of variation (CV \%).

\section{Subjects}

Twenty-eight junior rugby players (rugby union, $n=14$; rugby league, $n=14$ ) participated in the study (age $17.7 \pm 0.6$ years, height $180.9 \pm 6.4 \mathrm{~cm}$ and body mass $85.9 \pm$ $9.4 \mathrm{~kg}$ ) during mid-season. All players were familiar with the testing procedures and trained 
at the club two - three times per week including resistance training, aerobic conditioning, speed development and speed technique sessions. All experimental procedures were approved by the ethics committee with informed assent, and parental consent (for players under 18 years) obtained.

\section{Procedures}

Linear sprint: Sprints were assessed at 5, 10, 20, 30 and $40 \mathrm{~m}$ using single beam timing gates (Brower Timing Systems, IR Emit, USA). Single beam timing systems have been reported to increase the likelihood of false signals, whereby the infrared beam is broken by limbs rather than the torso (15). Despite this it has been suggested that this becomes negligible as distance increases, and that practitioners must place a cost to benefit upon testing technology (15). Distances were measured out using a $50 \mathrm{~m}$ tape measure. Marks were left on the $3 \mathrm{G}$ pitch to ensure the identical placement of speed gates between sessions. These distances were chosen to enable assessment of initial and maximal sprint capabilities as used by Barr et al. (4). Following a standardized warm up consisting of light jogging, dynamic stretches and submaximal sprint efforts, players completed three maximal sprints with three minutes rest between attempts. Subjects started each sprint from a two-point start, precisely $50 \mathrm{~cm}$ behind the first timing gate, with players instructed to set off in their own time and run maximally through the final $40 \mathrm{~m}$ timing gate. Players were verbally encouraged to run as fast as possible through the $40 \mathrm{~m}$ timing gate, and only decelerate after this. The best of the three times for each split was taken for analysis with times measured to the nearest $0.01 \mathrm{~s}$ on each occasion.

\section{Statistical Analysis}

Data are presented as either mean $\pm S D$ or means with $90 \%$ confidence intervals $(90 \%$ CI) where specified. Data analysis was completed in the following order; 
1) Data were examined to determine if any between code differences existed to ensure findings were applicable to both rugby union and rugby league.

2) Differences between consecutive trials were examined to determine if any learning effects existed.

3) between-day reliability for consecutive trials was determined, alongside the SWC, and test rating.

Parts 1 and 2 were examined using magnitude based inferences (20), with between code effects examined using a pooled $S D$ as groups were independent, whilst consecutive trials used $S D$ of trial 1 to ascertain short-term reliability. Between code and consecutive trial differences were measured to assess if split times were lower, similar, or greater than the SWC or smallest practical difference (SPD). The probability that the magnitude of the difference was greater than the SWC/ SPD was rated as $<0.5 \%$, almost certainly not; $0.5-5 \%$, very unlikely; 5-25\%, unlikely; 25-75\%, possibly; 75-95\%, likely; 95-99.5\%, very likely; $>99.5 \%$ almost certainly. Differences less than the SWC/ SPD were described as trivial. Where the $90 \%$ Confidence Interval $[\mathrm{CI}]$ crossed both the upper and lower boundaries of the SWC/ SPD (ES \pm 0.2$)$ the magnitude of the difference was described as unclear.

If any between code differences were identified for a split time it was removed from reliability analysis, as it would not accurately reflect the TE and SWC for a specific rugby code.

Part 3 between-day reliability was determined by calculating TE as follows;

$$
\mathrm{S}_{\mathrm{diff}} / \sqrt{2}
$$

with $\mathrm{S}_{\mathrm{diff}}$ as the standard deviation of the difference score (21) using a Microsoft Excel spreadsheet (19) and, expressed as raw TE (seconds) and as a CV (\%). It is important to 
acknowledge that having the best reliability does not mean a variable is the most useful at measuring something valuable, as a number of physiological measures have high reliability but may not be sensitive to measurement tools (23). Despite this a CV $<5 \%$ was set as the criterion to declare that a variable was reliable as previously reported $(6,9)$. The usefulness of the test was assessed by comparing the SWC with the TE (23). It is important to understand that in tests where the TE is greater than the SWC, the test is considered as not sensitive, as the detection of biological change is not possible due to the associated error in

measuring the test. If the TE was less than the SWC the test was considered as "good"; if the TE was similar to the SWC this was considered as "OK"; and where the TE was greater than the SWC the test usefulness was considered as "marginal" (22).

\section{RESULTS}

Between code differences. The differences in sprint time at each split demonstrated that rugby league players were likely faster than rugby union players at $5 \mathrm{~m}$, with further comparisons unclear (Table 1). Five meter splits were removed from the between-day reliability analysis so that the findings were applicable to both rugby union and rugby league.

\footnotetext{
***Insert Table 1 near here***
}

Reliability. Sprint time at each split interval is shown in table 2, with table 3 displaying the TE and CV\%. Effect size' demonstrated small (-0.28) improvements in sprint time between trials for $10 \mathrm{~m}$. Further comparisons revealed no differences between trials 1 and 2. TE was considered reliable for all distances $(<5 \%)$. 
***Insert Table 2 near here***

*** Insert Table 3 near here***

Test Usefulness. The TE values for all split times were greater than the SWC, giving the test a rating of marginal for usefulness (Table 3).

\section{DISCUSSION}

Due to the emphasis placed on the evaluation of acceleration and maximal speed derived from linear sprint testing in team sports $(3,4,17,24,32)$, we investigated the reliability and usefulness of a 40m linear sprint test in adolescent rugby players. The main finding from the present study was that 10,20,30 and $40 \mathrm{~m}$ time are reliable when using a single beam timing system, with players starting $50 \mathrm{~cm}$ behind the start of a sprint; with $\mathrm{CV}$ values corresponding to $3.1 \%, 1.8 \%, 2.0 \%$ and $1.3 \%$, respectively. Further findings show that short acceleration $(5 \mathrm{~m})$ ability is greater in rugby league than rugby union players, and that code specific TE and SWC need to be generated for this distance.

While the CV\% at 10, 20, 30 and 40 m demonstrates good reliability, the test was unable to detect the SWC at any of the split distances, as the TE was consistently greater than the calculated SWC giving the test a usefulness of marginal. This suggests that when practitioners interpret sprint times in adolescent rugby players, the reliability and usefulness of the test must be accounted for when inferring whether a change in performance has occurred. 
The TE at each split in the present study ranged from $0.05-0.08 \mathrm{~s}$ suggesting that the error is consistent across the distance of a sprint. However when expressed as a CV\%, the TE generally decreases with sprint distance, suggesting that sprinting over longer distances (> $20 \mathrm{~m}$ ) is more reliable in adolescent rugby players. Similar associations between error and distance have been reported when measuring linear speed with a lazer based device, and are in agreement with the current study, with the lazer reliable at distances of $10 \mathrm{~m}$ or greater (5). The small difference between session one and two in $10 \mathrm{~m}$ split time may highlight variations in the timing, magnitude and application of mechanical horizontal force that is required to accelerate (8). Recent recommendations have been made regarding optimising acceleration capabilities in elite rugby union and league players with horizontally orientated resistance exercises to maximise horizontal force production, thus improving acceleration ability (11).

Despite the usefulness of sprint times at each split being rated as 'marginal', Hopkins (22) has proposed a method whereby plotting the change score of the individual $( \pm \mathrm{TE}$ expressed as a CV\%) against the SWC is capable of visualising when a change has occurred (figure 1). A change is only called clear when the change score ( \pm TE expressed as a CV \%) is outside of the SWC; where the TE crosses into the SWC this is called unclear. This method allows practitioners to determine that a change is greater than the SWC with a $75 \%$ probability which has been deemed acceptable in the applied setting $(14,18,26)$; allowing better informed judgements on the changes in performance of their athletes on an individual level, and when assessing the effectiveness of training programs.

***Insert Figure 1 near here***

With the current reliability data in mind, it is now possible for researchers to plot individual changes for participants in studies involving adolescent rugby union and league players to determine if players improved both beyond the TE and practically ( $>$ SWC). For 
example Till et al., (31) reports seasonal improvement of $0.03 \mathrm{~s}(1.82 \pm 0.06 \mathrm{~s}$ to $1.79 \pm 0.07$ $\mathrm{s} ; p \leq 0.05)$ and $0.04 \mathrm{~s}(1.83 \pm 0.09 \mathrm{~s}$ to $1.79 \pm 0.11 \mathrm{~s} ; p \leq 0.05)$ over $10 \mathrm{~m}$, and $0.05 \mathrm{~s}(3.14 \pm$ $0.10 \mathrm{~s}$ to $3.09 \pm 0.11 \mathrm{~s} ; p<0.01)$ and $0.06 \mathrm{~s}(3.15 \pm 0.21 \mathrm{~s}$ to $3.09 \pm 0.20 \mathrm{~s} ; p \leq 0.05)$ over 20 $\mathrm{m}$ in under 18 and under 20 annual age categories respectively in rugby league players. Using these data and the pre-test $S D$ as the standardiser all improvements in sprint times were small (under 18s, $10 \mathrm{~m} \mathrm{ES}=-0.50,20 \mathrm{~m} \mathrm{ES}=-0.50$; under 20s, $10 \mathrm{~m} \mathrm{ES}=-0.44,20 \mathrm{~m} \mathrm{ES}=-$ 0.29) over a season. Despite this, the readers are unaware of improvement, stability or decreases in performance at an individual level, which in the applied setting is arguably more important, especially when making recommendations regarding long term career progression, development, and in the evaluation of training interventions.

Although the present study is the first to report between-day reliability for a linear sprint test in junior rugby union and rugby league players, some limitations exist that if addressed could further improve the reliability associated with linear sprint tests using a single beam timing system. Standardization of the start position with regards to shin angle and stance width may reduce variation during the initial sprint. Furthermore air temperature and wind speed were not measured in the present study, both of which impact upon air resistance and sprint speed (2). Finally, increasing the sample size and number of trials is known to increase the precision of the TE in reliability studies (21), which was not possible in the present study due to time constraints and player availability.

In conclusion, the present study investigated the between-day reliability of a linear sprint test in junior rugby union and rugby league players. The findings demonstrate that junior rugby league players are faster over $5 \mathrm{~m}$ than junior rugby union players, with further differences at 10, 20, 30 and $40 \mathrm{~m}$ unclear. Between-day reliability of 10, 20, 30 and $40 \mathrm{~m}$ was acceptable $(<5 \%)$, but greater than the SWC at each split rating the test as marginal. We recommend that practitioners and researchers use the TE alongside the SWC to make an 
informed decision on whether a change is both real (greater than the noise of the test, i.e., $>$ TE) and of practical significance (>SWC), as proposed by Hopkins (22).

\section{PRACTICAL APPLICATIONS}

Both researchers and practitioners can use the current findings to ensure that individual changes in performance at 10,20, 30 and $40 \mathrm{~m}$ during a linear sprint are monitored effectively. The method proposed can be used to demonstrate individual responses to training interventions alongside group-mean data to improve the dissemination of research findings. This can be done in the applied setting by plotting the change score at each split $( \pm \mathrm{TE}$ expressed as a CV) against the SWC, and visually inspecting whether the TE crosses the SWC.

\section{ACKNOWLEDGEMENTS}

The authors would like to thank Andrew Rock (Academy director) and the players who were involved in the project. This research was part funded by Leeds Rugby as part of the Carnegie Adolescent Rugby Research (CARR) project. 



\section{REFERENCES}

1. Altmann S, Hoffmann M, Kurz G, Neumann R, Woll A, and Haertel S. Different Starting Distances Affect 5-m Sprint Times. J Strength Cond Res 29: 2361-2366, 2015.

2. Arsac LM and Locatelli E. Modeling the energetics of 100-m running by using speed curves of world champions. J Appl Physiol (1985) 92: 1781-1788, 2002.

3. Baker D and Nance S. The relation between running speed and measures of strength and power in professional rugby league players. J Strength Cond Res 13: 230-235, 1999.

4. Barr MJ, Sheppard JM, Gabbett TJ, and Newton RU. Long-term training-induced changes in sprinting speed and sprint momentum in elite rugby union players. $J$ Strength Cond Res 28: 2724-2731, 2014.

5. Bezodis NE, Salo AI, and Trewartha G. Measurement error in estimates of sprint velocity from a laser displacement measurement device. Int J Sports Med 33: 439444, 2012.

6. Buchheit M, Lefebvre B, Laursen PB, and Ahmaidi S. Reliability, usefulness, and validity of the 30-15 Intermittent Ice Test in young elite ice hockey players. $J$ Strength Cond Res 25: 1457-1464, 2011.

7. Buchheit M, Rabbani A, and Beigi HT. Predicting changes in high-intensity intermittent running performance with acute responses to short jump rope workouts in children. J Sports Sci Med 13: 476-482, 2014.

8. Buchheit M, Samozino P, Glynn JA, Michael BS, Al Haddad H, Mendez-Villanueva A, and Morin JB. Mechanical determinants of acceleration and maximal sprinting speed in highly trained young soccer players. J Sports Sci 32: 1906-1913, 2014. 
9. Buchheit M, Spencer M, and Ahmaidi S. Reliability, usefulness, and validity of a repeated sprint and jump ability test. Int J Sports Physiol Perform 5: 3-17, 2010.

10. Cohen J. Statistical power analysis for the behavioral sciences. Routledge Academic, 2013.

11. Cross MR, Brughelli M, Brown SR, Samozino P, Gill ND, Cronin JB, and Morin JB. Mechanical Properties of Sprinting in Elite Rugby Union and Rugby League. Int J Sports Physiol Perform 2014.

12. Darrall-Jones J, Jones B, and Till K. Anthropometric and Physical Profiles of English Academy Rugby Union Players. J Strength Cond Res 29: 2086-2096, 2015.

13. Duthie G, Pyne D, and Hooper S. Applied physiology and game analysis of rugby union. Sports Med 33: 973-991, 2003.

14. Duthie GM, Pyne DB, Ross AA, Livingstone SG, and Hooper SL. The reliability of ten-meter sprint time using different starting techniques. J Strength Cond Res 20: 246251,2006

15. Earp JE and Newton RU. Advances in electronic timing systems: considerations for selecting an appropriate timing system. J Strength Cond Res 26: 1245-1248, 2012.

16. Gabbett TJ. Influence of physiological characteristics on selection in a semiprofessional first grade rugby league team: a case study. J Sports Sci 20: 399-405, 2002.

17. Hoffman JR, Fry AC, Howard R, Maresh CM, and Kraemer WJ. Strength, speed and endurance changes during the course of a division I basketball season. J Strength Cond Res 5: 144-149, 1991.

18. Hopkins W. Precision of the estimate of a subject's true value (Excel spreadsheet). In: A New View of Statistics sportsci org: Internet Society for Sport Science, sportsci.org/resource/stats/xprecisionsubject.xls. 2000. 
19. Hopkins W. Reliability from consecutive pairs of trials (Excel spreadsheet). A New View of Statistics, 2000.

20. Hopkins W, Marshall S, Batterham A, and Hanin J. Progressive statistics for studies in sports medicine and exercise science. Med Sci Sports Exerc 41: 3, 2009.

21. Hopkins WG. Measures of reliability in sports medicine and science. Sports medicine (Auckland, NZ) 30: 1-15, 2000.

22. Hopkins WG. Measures of reliability in sports medicine and science. Sports Med (Auckland, NZ) 30: 1-15, 2000.

23. Hopkins WG, Schabort EJ, and Hawley JA. Reliability of power in physical performance tests. Sports Med 31: 211-234, 2001.

24. McGee KJ and Burkett LN. The National Football League combine: a reliable predictor of draft status? J Strength Cond Res 17: 6-11, 2003.

25. Moir G, Button C, Glaister M, and Stone MH. Influence of familiarization on the reliability of vertical jump and acceleration sprinting performance in physically active men. J Strength Cond Res 18: 276-280, 2004.

26. Pyne DB. Interpreting the Results of Fitness Testing. Presented at International Science and Football Symposium, Melbourne, Australia, 2003.

27. Pyne DB, Spencer M, and Mujika I. Improving the value of fitness testing for football. Int J Sports Physiol Perform 9: 511-514, 2014.

28. Rumpf MC, Cronin JB, Oliver JL, and Hughes M. Assessing youth sprint abilitymethodological issues, reliability and performance data. Ped Ex Sci 23: 442-467, 2011.

29. Seitz LB, Barr M, and Haff GG. Effects of Sprint Training With or Without Ball Carry in Elite Rugby Players. Int J Sports Physiol Perform 10: 761-766, 2014. 
30. Till K, Jones B, Darrall-Jones J, Emmonds S, and Cooke C. The longitudinal development of anthropometric and physical characteristics within academy rugby league players. J Strength Cond Res 29: 1713-1722, 2014.

31. Till K, Jones B, Emmonds S, Tester E, Fahey J, and Cooke C. Seasonal changes in anthropometric and physical characteristics within english academy rugby league players. J Strength Cond Res 28: 2689-2696, 2014.

32. Young WB, Newton RU, Doyle TL, Chapman D, Cormack S, Stewart G, and Dawson B. Physiological and anthropometric characteristics of starters and non-starters and playing positions in elite Australian Rules Football: a case study. J Sci Med Sport 8: 333-345, 2005. 
Figure 1. An example of a change in performance of an athlete. Data are percentage change ( $\pm \mathrm{CV}$ as error bars) with the grey area representing the smallest worthwhile change. Both the black and white circle represent percent changes in $10 \mathrm{~m}$ sprint time of 3.8\%. The black circle change is greater than both the TE (3.05\%) and the SWC combined, therefore represents a $75 \%$ probability that the change is greater than the SWC. The white circle demonstrates that a larger TE $(3.75 \%)$ would not allow the practitioner to detect a change as the TE crosses into the SWC. 
Table 1. Linear speed testing split times at $5 \mathrm{~m}, 10 \mathrm{~m}, 20 \mathrm{~m}, 30 \mathrm{~m} \& 40 \mathrm{~m}$, for rugby union and rugby league players

\begin{tabular}{|c|c|c|c|c|c|}
\hline & $5 \mathrm{~m}$ & $10 \mathrm{~m}$ & $20 \mathrm{~m}$ & $30 \mathrm{~m}$ & $40 \mathrm{~m}$ \\
\hline Rugby Union (s) & $1.04 \pm 0.04$ & $1.80 \pm 0.06$ & $3.12 \pm 0.10$ & $4.36 \pm 0.16$ & $5.57 \pm 0.22$ \\
\hline Rugby League (s) & $1.01 \pm 0.03$ & $1.79 \pm 0.04$ & $3.10 \pm 0.06$ & $4.30 \pm 0.10$ & $5.57 \pm 0.11$ \\
\hline $\mathrm{ES}[90 \% \mathrm{CI}]$ & $-0.74[-1.37 ;-0.12]$ & $-0.24[-0.87 ; 0.38]$ & $-0.12[-0.75 ; 0.50]$ & $-0.22[-0.85 ; 0.40]$ & $0.04[-0.59 ; 0.66]$ \\
\hline $\begin{array}{c}\text { Probability } \\
\text { (greater/ similar/lower) } \\
\text { split time }\end{array}$ & $(1 / 7 / 92)$ & $(12 / 33 / 55)$ & $(19 / 39 / 42)$ & $(13 / 35 / 52)$ & $(33 / 41 / 26)$ \\
\hline Inference & $\begin{array}{l}\text { RL likely lower split } \\
\text { time }\end{array}$ & Unclear & Unclear & Unclear & Unclear \\
\hline
\end{tabular}


Table 2. Linear speed testing split times at $10 \mathrm{~m}, 20 \mathrm{~m}, 30 \mathrm{~m} \& 40 \mathrm{~m}$, combined mean $( \pm \mathrm{SD})$ and differences between sessions used to determine between-day reliability.

\begin{tabular}{c|cccc} 
& $10 \mathrm{~m}$ & $20 \mathrm{~m}$ & $30 \mathrm{~m}$ & $40 \mathrm{~m}$ \\
\hline Session 1 (s) & $1.81 \pm 0.06$ & $3.12 \pm 0.10$ & $4.34 \pm 0.14$ & $5.55 \pm 0.19$ \\
Session 2 (s) & $1.79 \pm 0.06$ & $3.10 \pm 0.09$ & $4.35 \pm 0.15$ & $5.58 \pm 0.17$ \\
Combined Sessions (s) & $1.80 \pm 0.06$ & $3.11 \pm 0.09$ & $4.34 \pm 0.14$ & $5.57 \pm 0.18$ \\
Difference [90\% CI] & $-0.02[-0.04 ; 0.01]$ & $-0.01[-0.04 ; 0.01]$ & $0.01[-0.03 ; 0.05]$ & $0.03[-0.01 ; 0.06]$ \\
ES [90\% CI] & $-0.28[-0.67 ; 0.11]$ & $-0.11[-0.36 ; 0.14]$ & $0.06[-0.20 ; 0.32]$ & $0.14[-0.03 ; 0.30]$ \\
Probability & $(2 / 35 / 63)$ & $(2 / 71 / 27)$ & $(19 / 76 / 5)$ & $(26 / 74 / 0)$ \\
(greater/ similar/lower) & Session 2 possibly & Possibly trivial & Likely trivial & Possibly trivial \\
split time & differences & differences & differences
\end{tabular}

Table 3. Measures of reliability for linear speed testing at 10m, 20m, 30m \& 40m

\begin{tabular}{c|cccc} 
& $10 \mathrm{~m}$ & $20 \mathrm{~m}$ & $30 \mathrm{~m}$ & $40 \mathrm{~m}$ \\
\hline TE $(\mathrm{s})[90 \% \mathrm{CI}]$ & $0.05[0.04 ; 0.07]$ & $0.06[0.05 ; 0.07]$ & $0.08[0.07 ; 0.11]$ & $0.07[0.06 ; 0.09]$ \\
TE CV\% [90\% CI] & $3.05[2.50 ; 3.96]$ & $1.82[1.49 ; 2.36]$ & $1.95[1.60 ; 2.53]$ & $1.33[1.09 ; 1.73]$ \\
SWC (s) (\%) & $0.01(0.67)$ & $0.02(0.59)$ & $0.03(0.67)$ & $0.04(0.64)$ \\
Test Rating & Marginal & Marginal & Marginal & Marginal
\end{tabular}

$* \mathrm{TE}=$ typical error of measurement; $90 \% \mathrm{CI}=90 \%$ confidence intervals; TE CV $\%=$ typical error of measurement expressed as a coefficient of variation; $\mathrm{SWC}=$ smallest worthwhile change 


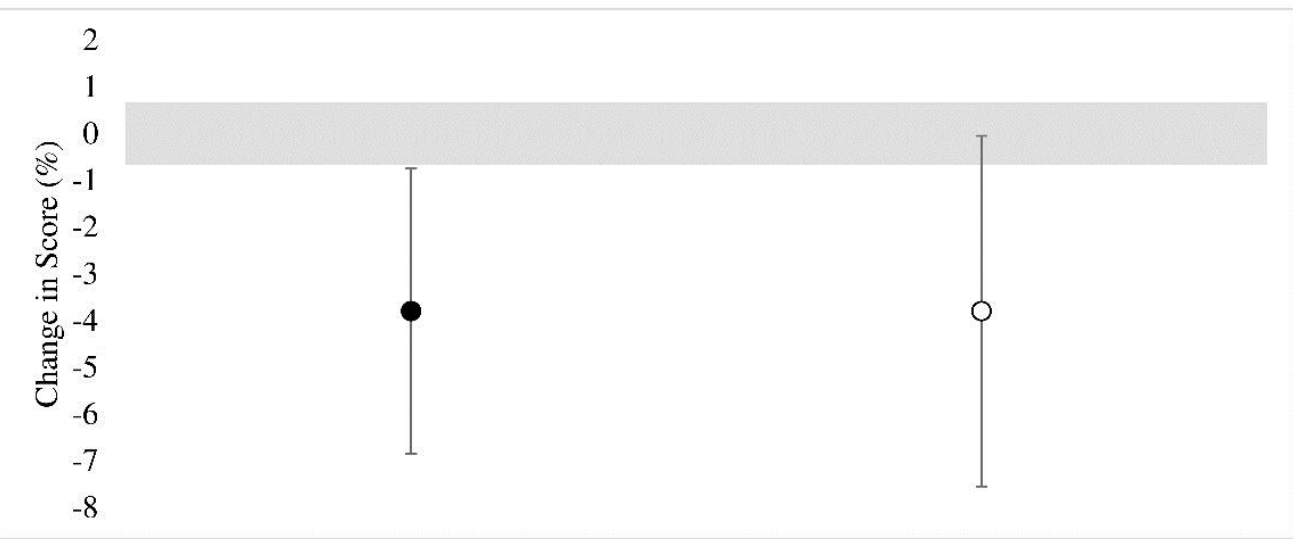

